\title{
Asthma as a Respiratory Disorder: A Review
}

\section{Sadia Sidra Aziz* and Razia Iqbal}

\author{
Department of Zoology, University of Gujrat, Gujrat, Pakistan, \\ *sadia.sidra.aziz@gmail.com
}

\begin{abstract}
This article reviews causes, symptoms and genetic basis of asthma as well as the pharmaceutical therapies currently being practiced for its treatment. Asthma is a worldwide respiratory disorder characterized by recurring conditions of inflammation and the narrowing of respiratory passage ways termed as bronchoconstriction, bronchial hyper-responsiveness, bronchospasm, chest tightening, shortness of breath, etc. About 300 million people suffer from asthma globally with 250,000 annual deaths attributed to asthma. In many populations, the main cause of an increased occurrence of asthma is the lack of awareness among general public. Smoking, allergens, microbes, pollutants, dust, chemicals, vapors, fumes, exercise etc. act as stimulants and triggers of asthma. Various gene-gene and genetic-environmental factors act together resulting in asthmatic pathogenesis. Various loci have been identified that play a potential role in this regard. Genetic polymorphism among patients makes the treatment a bit difficult as patients with similar symptoms show varied responses to the same medications and therapeutic strategies. Asthma is not completely curable; therefore, most medications aim to lower the exacerbations rather than fixing the underlying causes and mechanisms of the disease. Short and Long Acting Beta-antagonists (SABAs and LABAs) and inhaled corticosteroids (ICS) have been found to be effective against asthma. Phytomedicines and biological agents such as omalizumab are being developed currently for the modulation of asthma-related immunologic and cell-signaling mechanisms. Asthma and psychological disorders are often found to be correlated. The need arises for greater public awareness regarding asthma, improved genetic analysis techniques, assessment of underlying molecular mechanisms, optimization of current therapeutic strategies and the development of new personalized target drugs for its efficient prevention and control.
\end{abstract}

Keywords: asthma, bronchial hyper-responsiveness, bronchospasm, SABAs, LABAs, ICS

\section{Introduction}

Asthma is a common respiratory disease caused by partially reversible inflammation of the air passage ways of lungs and elevated responsiveness to triggers [1]. It is characterized by bronchospasm, i.e., constriction of muscles in bronchioles [2], obstructive airflow, recurring symptoms such as wheezing, short breath, coughing, tightness of chest etc. [3]. Symptoms may show up repeatedly 
and can get worse after exercise or at night [2]. It is the most prevailing disease among children in approximately all of the industrialized countries. A range of triggers provoke the disease, e.g., dust, allergens, vapors, viruses, chemicals, tobacco smoke, microorganisms, air of poor quality, infectious agents, fumes, exercise etc. [4]. Stimulants unrelated to allergy, e.g., physical activity, negative emotions, perfumes, and air pollution can also lead towards asthma [5]. Approximately 300 million people are affected by asthma every year and 250,000 annual deaths occur due to asthma [6].

The main characteristic of asthma is the inflammation of respiratory passages that varies in different cases reflecting different aspects of this disease, e.g., persistent, intermittent, acute and chronic types. Inflammation is caused by the action of mast cells, eosinophils, neutrophils, dendritic cells, macrophages, cells of air passages, epithelial cells; while chemokines, cytokines mainly IL-9, IL-4, IL13, IL-5, and GM-CSF; nitric oxide, cysteinyl-leukotrienes and IgE act as inflammatory mediators. Acute asthma is generally caused by bronchospasm and can be cured by bronchodilator treatment [7]. Asthma has been divided into various categories depending upon the nature of variation of the disease. These include occupational non-IgE-dependent asthma, atopic asthma, aspirin-intolerant asthma (AIA), cough variant asthma, intrinsic asthma, and brittle asthma [8].

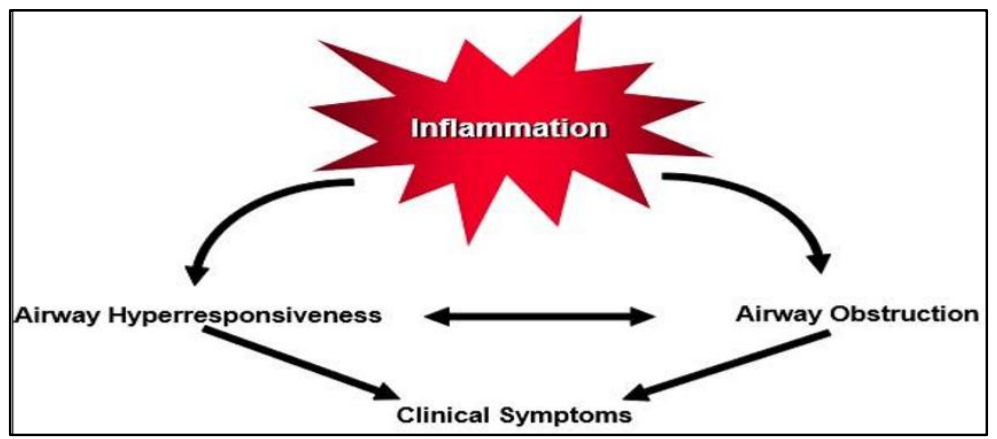

Figure 1. The relationship between the obstruction of air passages and symptoms of asthma [7]

\section{History and Background}

The first recorded report on the account of asthma dates back to ancient Egypt where it was treated by a mixture known as "Kyphi" [9]. It was named by Hippocrates as 'specific respiratory problem' in $450 \mathrm{BC}$ [10]. In $12^{\text {th }}$ century, Maimonides wrote about asthma in Arabic, discussing about its various symptoms and possible treatments with an emphasis on clean environment [11]. In 1872, it was discovered that asthma could be treated by rubbing chloroform liniment on the chest. Researchers attempted to uncover the pathophysiology of the disease in 1873 $[12,13]$. Various drugs were introduced for the treatment of asthma such as intravenous pilocaprin in 1880, epinephrine in 1905, oral corticosteroids in 1950s, 
and inhaled corticosteroids and short chained beta agonists came into wide use in 1960s [14-17]. Later, asthma was thought to be linked with emotional stress and depression, therefore treatment linked psychoanalysis with the respiratory cures [18].

\subsection{Causes of Asthma}

Asthma may be attributed to a wide range of reasons when asthmatic agents enter circulatory system and cause inflammation [19]. It has been observed that about $15-60 \%$ of patients undergo poor symptom perception where they either exaggerate their symptoms causing excessive use of medication or there is an under-perception of symptoms that results in delayed onset of treatment [20]. In addition, alexithymia also influences the perception and recognition of disease symptoms by the patients [21].

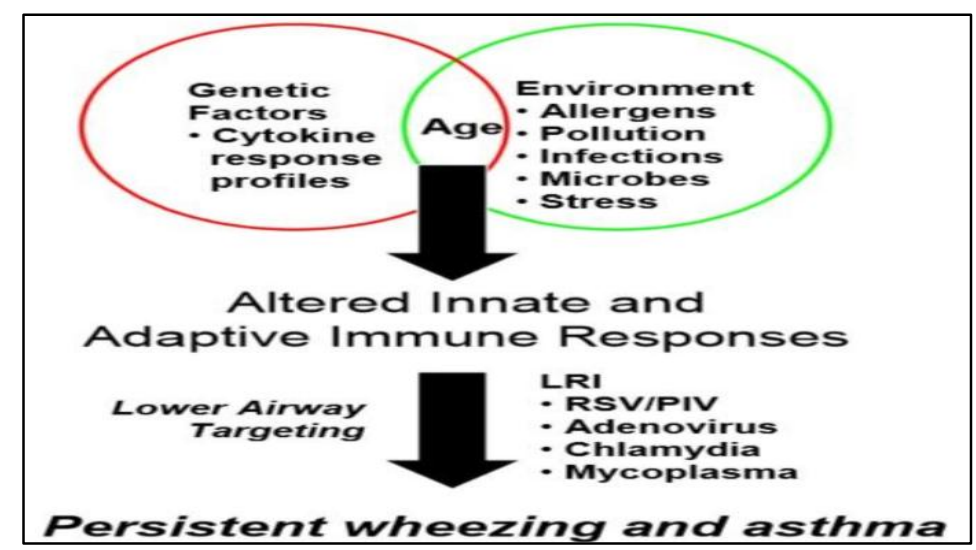

Figure 2. The relation between host factors, age and environmental exposure in pathogenesis of asthma; LRI: lower respiratory illnesses; RSV: respiratory syncytial virus; PIV: parainfluenza virus

Occupational exposure to many triggers and allergens results in asthma. Exposure of workers to palladium-containing electroplating bath can induce asthma in them [22]. Exposure to air pollution caused by traffic leads to asthma [23]. 22 species of plants have been described to induce this disease, e.g., pinewood and ipe that contains naphtoquinones that are sensitizers for skin. Therefore workers exposed to wood dust are at an elevated risk to acquire asthma [24,25]. Construction workers have also been reported to exhibit asthmatic symptoms [26]. Exercise Induced Bronchoconstriction (EIB) is reported to contribute towards asthma [27].

Exposure to oxidative pollutants in the air such as tobacco smoke, $\mathrm{NO}_{\mathrm{x}}$, ozone and particulates has been observed to make the disease worse [28]. Respiratory viral infections, e.g., coronavirus, rhinovirus and influenza virus exacerbate the problem [29]. Cleaners are also prone to the disease especially those who use spray bleaches [30]. Swimming trainers and swimming pool cleaners are susceptible to asthma because of chloramines formed as product of reaction 
between chlorine with urine and sweat of swimmers [31]. Viruses of the common cold reportedly worsen asthmatic condition [32]. Maternal exposure to polycyclic aromatic hydrocarbons mostly related to traffic can induce methylation in gene ACSL3, precisely on CpG island, attributing to asthma in the baby [33].

\subsection{Symptoms of Asthma}

Asthma is characterized by a wide variety of symptoms that can vary from person to person. Initial symptoms of asthma include wheezing or whistling sound associated with breathing. Cough, breathlessness, and tightening of chest typify the disease. Asthma is often associated with allergy characterized by immunologically mediated, rapidly enhancing responsiveness. Adversative immune responsiveness that involves $\operatorname{IgE}$ antibodies referred to as atopy is the foremost predisposal indication of developing asthma [34]. Following are the alterations in the airways that lead towards the pathogenesis of asthma,

Bronchoconstriction involves the narrowing of air passages and restricted airflow. In severe cases, when a person is exposed to any trigger or allergen, smooth muscles in the bronchi contract quickly and make the passages narrow. Acute type of bronchoconstriction caused by any allergen is due to IgE-based mediator release of prostaglandins, leukotrienes, tryptase and histamine from mast cells. These chemicals interact with smooth muscles directly [35]. Certain medications can also induce bronchoconstriction, e.g., aspirin and some anti-inflammatory drugs especially those which do not contain steroids [36]. Edema of the airways results from the higher level of airway inflammation along with hypersecretion of mucus, mucus plug formation, hyperplasia and hypertrophy of smooth muscles. Hyperresponsiveness of airways can be caused by various stimuli and is determined mainly by the degree of airway inflammation along with structural alterations and dysfunctional neuro-regulation. Treatments that reduce inflammation also help to reduce hyper-responsiveness. Remodeling of airways is the nearly permanent alteration in the air passages that can lead progressively towards the loss of lung function. These alterations can be hypersecretion and hyperplasia of mucous glands, thickened sub-basement membranes, proliferation and dilation of blood vessels, hyperplasia and hypertrophy of respiratory smooth muscles, sub-epithelial fibrosis etc. Currently these types of changes are not cured completely by treatments [37]. 


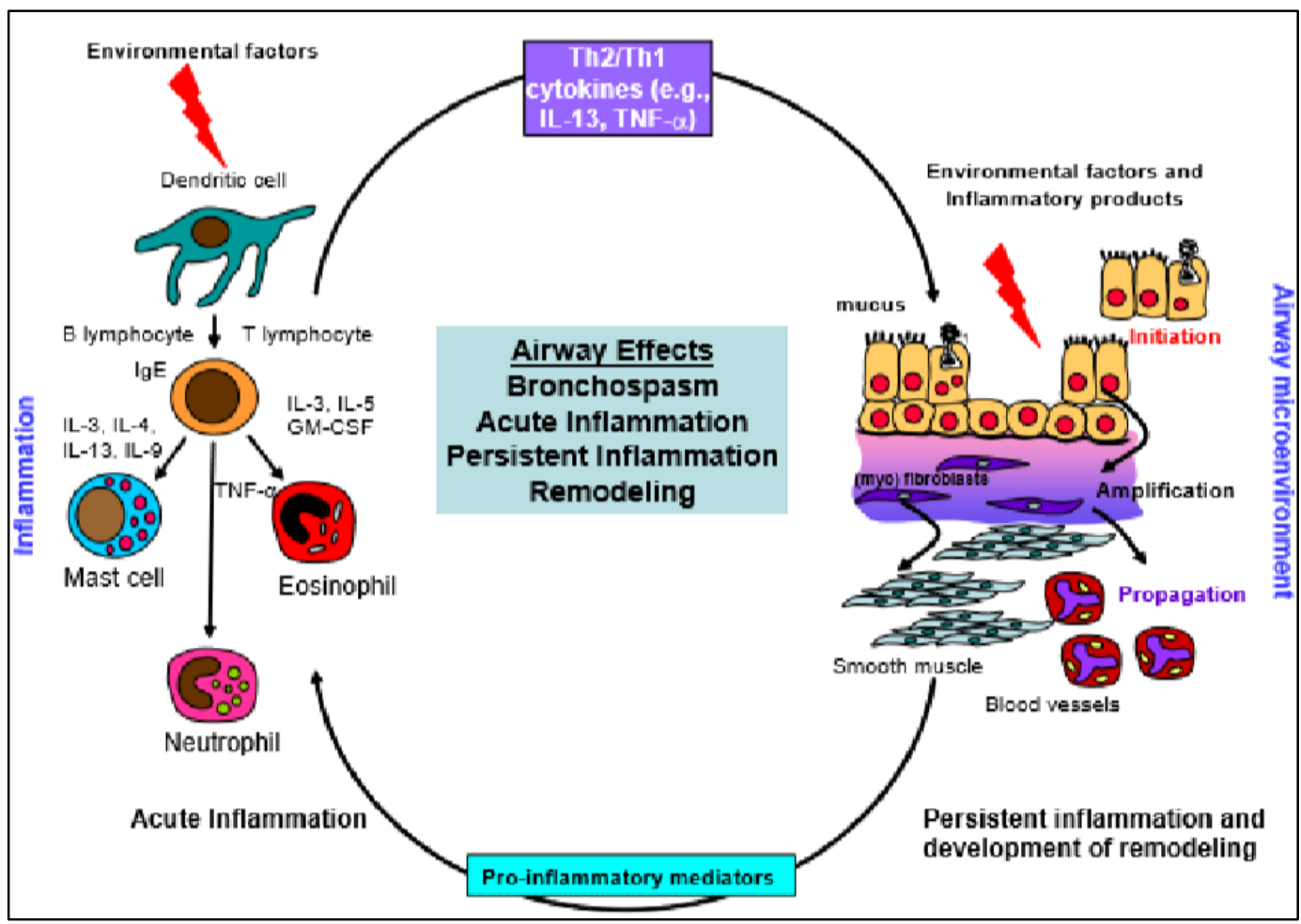

Figure 3. Few factors that contribute in limited airflow [37]

\subsection{Genetic Basis of Asthma}

Several genetic studies have indicated a $60 \%$ heritability of asthma [38]. Numerous environmental and genetic factors interact to result in complex allergic diseases including asthma. First degree relatives of asthma patients are at a 5-6 times higher risk to acquire the disease than others [39]. Range of genetic heritability for asthma varies from 0.48-0.79 [40]. Several genes are being identified that are involved in the asthmatic pathogenesis. Locus ORMDL3 / GSDMD on 17q21 chromosome has reportedly shown to be involved in the commencement of childhood asthma [41].

Different approaches are utilized for unveiling the underlying genetic mechanisms of the disorder. For example, in Positional Cloning also known as genome wide linkage studies or genome scan, many genetic markers, e.g., polymorphic DNA markers, are employed for identifying genes responsible for the disease on suspected chromosomes. It can also identify genes that are previously unknown or unsusceptible genes [42]. Recently discovered genes related to asthma are SPRINK5 on chromosome number 5q31-35, ADAM33 on 20p, DPP10 on $2 q 14-32$, HLA-G on $6 \mathrm{p} 21$, IRAKM on $12 \mathrm{q}$, GPRA on $7 \mathrm{p}$, PHF11 on $13 \mathrm{q} 14$ chromosomes [43-49]. 
The second common approach for finding genes related to the disease is Candidate gene approach which involves the selection of a gene that is the potential cause of any pathological disease and the analysis of its genetic variants and linkage groups [50]. More than 100 genes have been found to be involved in the pathogenesis of asthma. Some genes such as CD14 and GSTP1 play their role in environmental interaction, HLA-DRB1 is involved in antigen presentation, STAT6, IL4, IL4R and IL13 play their role in cellular differentiation, IL10, CCL5 and LTA are responsible for immunoregulation, ADAM33 is involved in tissue remodeling, and ADRB2 is responsible for relaxation of smooth muscles in respiratory tracts. TGFb1, DPP10 IL18R1 and IL1RL1 are thought to be most actively involved in the pathogenesis of asthma [51]. However, different genes were found to be associated with asthma in different populations. This genetical polymorphism in the pathogenesis of the disorder makes the therapeutic strategies a bit difficult as the same medication may give rise to a varied response among different individuals.

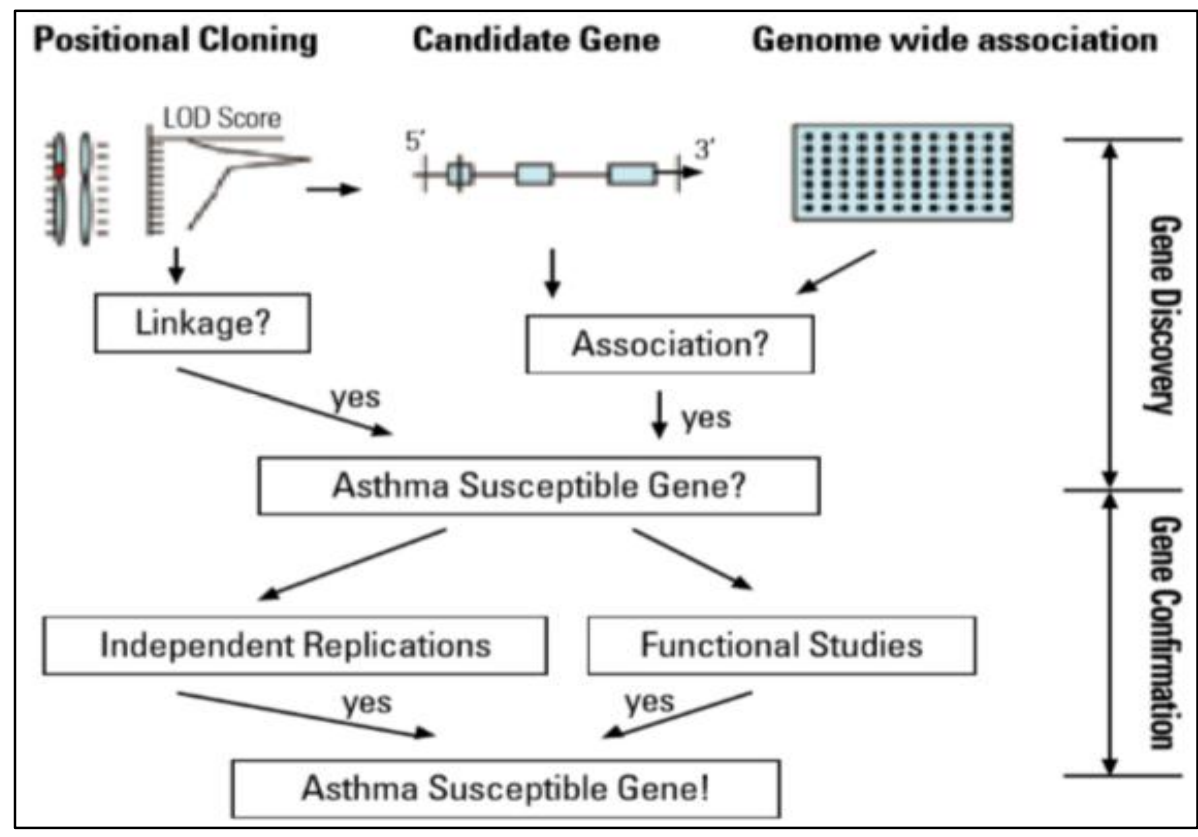

Figure 4. Flowchart depicting the steps for the investigation of genetic basis of asthma

Genetic Wide Association Study (GWAS) allows the comprehensive study of underlying mechanisms of a genetic disease by genomic analysis involving SNPs. Several variants and intervals have been found on various chromosomes in different populations that are known to have asthma. DPP10 PRNP and ADRA1B genes are associated with asthma in African populations. GWAS studies reveal the association of many functional, rare SNPs for asthmatic susceptibility, therefore heritability of asthma among families can be predicted. In the families where 
successive generations suffer from asthma, there is an $87 \%$ chance for their offsprings to have the disease. Twins, whose parents are asthmatic, have a four times increased risk of having the disorder as compared to the twins whose parents do not have asthma. The risk of acquiring the disease is even greater in monozygotic twins because of the shared genetic material as compared to dizygotic twins [52].

\subsection{Immunological Aspect of Asthma}

Depending upon the specific trigger involved, asthma can be regarded as intrinsic or extrinsic. Intrinsic asthma is thought to be non-immune with non-atopic history. On the other hand, extrinsic asthma occurs mostly due to hypersensitivity or anaphylactic reactions and as a consequence $\operatorname{IgE}$ level is elevated and so is the bronchial hyper-responsiveness to inhaled allergens whether specific or nonspecific [88]. Extrinsic asthma is the exaggerated response of immune system to otherwise harmless, most of which have either protease activity or any other deleterious effect. Infiltration into bronchial mucosa of mast cells, basophils, lymphocytes, eosinophils, macrophages, etc. and airway obstruction, remodeling and inflammation is brought about by the interaction of these cells with cells of respiratory tract, e.g., endothelium, epithelial cells, smooth muscle cells etc. [89].

Asthmatic patients experience an increased number of $\mathrm{CD}^{+} \mathrm{T}$ cells in respiratory passages along with an increased prevalence of $\mathrm{TH} 2$ cells as compared to TH1 cells found in the normal airways [94] due to the transcription factor GATA3 that carries out the transformation of non-committed T cells to TH2 cells and also influences the production of cytokines [95]. IL-4 and IL-13 produced by these cells influence B cells to synthesize $\operatorname{IgE}$ antibodies. Mast cells induce bronchoconstriction in asthmatic patients by releasing histamine, leukotriene $\mathrm{C} 4$, D4 and E4, prostaglandins D2,cytokines IL-4, IL-5 and IL-13 causing inflammation and collectively lead towards airway hyper-responsiveness [96].

For the explanation of the possible cause of asthma the "hygiene hypothesis" was proposed in 1980s. According to this hypothesis, immune hyperreactivity disorders result due to the lack of microbial fauna in the early stages of development [90]. Later on, asthmatic progression results from the bias of $\mathrm{T}$ helper cells towards Th2 phenotype [91]. According to some evidence, the polarization of immune system towards Th2 response during early developmental stages and exposure to microbes drives immune system towards Th1 response which is considered as a protective factor against asthma [92]. In asthmatic sputum, concentration of effector cytokine IL-17 produced by Th17 is elevated that plays a vital role in the progression of inflammatory asthmatic pathways [93].

\subsection{Treatment of Asthma}

The treatment of asthma was improved with the new advancements in the fields of medicine and pharmacology. Avoiding contact or exposure to allergens and triggers is an important precaution. Heterogeneity has been observed in patients

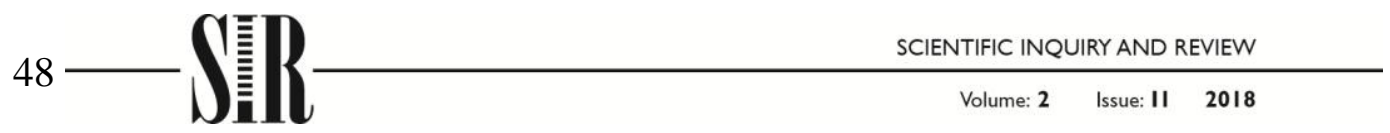


in response to several medications. Anti-inflammation medications help to cure airway obstruction and hyper-responsiveness but this process may take several weeks and may not be complete [53]. In some patients, the structure of respiratory passages may be altered which is known as airway remodeling. Currently available treatments have low efficiency against such type of cases ${ }^{[37]}$. At present, inhaled corticosteroids (ICS) and ICS with long acting beta2-agonists (LABA), e.g., salmeterol and formoterol are commonly used for treatment [54]. For increased effectiveness, LABAs are used in combination with corticosteroids [55]. Indacaterol and Fluticasone furoate-vilanterol are ultra-long-acting beta antagonists which are efficient in restoring airway function [56].

Short Acting Beta Agonists (SABAs) can cure bronchoconstriction irrespective of the nature of the trigger. Prolonged intake of corticosteroids via inhalation, e.g., ciclesonide, beclometasone, mometasone, budesonide, fluocinolide, and fluticasone etc., can improve air passages' functions and hyperresponsiveness [57]. Unfortunately, the effects of ICs fade after quitting the drug [58]. PDE4D inhibitors are being developed for asthma medication because they tend to suppress the activation of resident and inflammatory cells in response to various internal and external stimuli [59]. Leukotriene antagonists, e.g., montelukast have also been proved effective against asthma [60]. Long-acting muscarinic antagonists, e.g., aclidinium and tiotropium help in the dilation of bronchi and have been shown to increase the efficacy of corticosteroids and LABAs when used as a supplement [61].

Monoclonal antibodies such as Omalizumab that are directed against Immunoglobulin E are recommended to use in severe cases associated with atopy [57]. It has been repeatedly shown to be effective against a number of asthmatic exacerbations, however, it has only a limited usage because of high cost [62]. Recently an endoscopic procedure termed bronchial thermoplasty has been introduced which employs thermal energy for the disruption of smooth muscles of bronchi for the widening of airways, but this method is available only at specialized centers [63]. Currently, biologic agents such as Omalizumab are being synthesized which intends to modulate asthma-associated immunologic and cell signaling mechanisms.

Phytomedicine is another promising field for the development of effective medication against asthma without associated side effects. One such medicine is Atropine, derived from Atropa belladonna, is anti-muscarinic and acts on smooth muscles inhibiting their contraction and lowers the secretion of mucus. Unfortunately, atropine has been unsuccessful in lowering the exacerbating symptoms of asthma in clinical trials. Ipratropium bromide is the derivative of atropine and is significantly effective against bronchospasm [64]. Another notable medicine is ASHMI, i.e., anti-asthma herbal medicine intervention. It reduces hyper-responsiveness, prevents narrowing of airways by inhibiting constriction of 
tracheal ring induced by acetylcholine, enhances the production of prostacyclin and prostaglandin I2 [65]. Aleurites moluccana tree extracts are effective against asthma, inflammation, nociception, headache, fever, etc. [66].

Very recently, it was discovered that asthmatic patients have $50 \%$ reduction in protein metallothionein-2 (MT-2) that is involved in relaxation of smooth muscles and opening of airways. The absence of this protein in mice makes them 2 times more susceptible to asthma. After examining about 6000 drugs, researchers identified a compound named TSG12 that does the same function as MT-2 in egg and mite-induced asthma [86]. Despite the success of currently available treatment methods, the variable nature of asthma demands the innovation of new treatments. This can be attributed to several reasons such as recurrence of symptoms after leaving the medications, side effects of prescribed drugs and non-reversal airway remodeling of respiratory passages as ICs fail to inhibit IL-33 mediator of airway remodeling [67]. The novel approaches to drug designs aim to target the underlying asthma-related genetic mechanisms.

\subsection{Psychological Aspects in Asthma}

Many patients do not respond to common ICS and LABA treatment and the underlying reasons have a psychological basis [68]. It is an established fact that a link is present between mental health and asthma and both of these influence each other [69]. Asthma patients that are under the influence of an elevated level of negative emotionality undergo dyspnea more frequently, while in positive emotional state dyspnea is under-perceived [70]. Alexithymia influences social, psychological and emotional aspects of a person's life, which in the case of asthma patients leads them to underestimate the severity of the disease [71]. Patients who lack active coping strategies and have an avoidance attitude towards the symptoms or the severity of the disease tend to have difficult-to-cure asthma [72].

For a long time, asthma has been associated with anxiety, depression and mood disorders [73]. In fact, asthma patients show an elevated level of anxiety and depressive disorders than general public [74]. The more severe the disease is, the more severe are the psychological disorders and vice versa, especially among children and young adults [75]. Patients with uncontrolled asthma have a higher frequency of anxiety as compared to those with controlled asthma [76]. Systemic inflammations are considered a link between mood disorders and asthma along with a possible role of cytokines for nervous transmission in CNS [77].

\subsection{Asthma in Pakistan}

Currently, more than 20 million individuals in Pakistan are suffering from asthma. Out of this number, only $9.5 \%$ of the cases have been reported [78]. There is a great diversity among patients regarding the genetic variability of asthma as more than hundred loci are discovered to be somehow associated with asthmatic complications in the country [79]. As asthma is a multi-factorial disorder, several

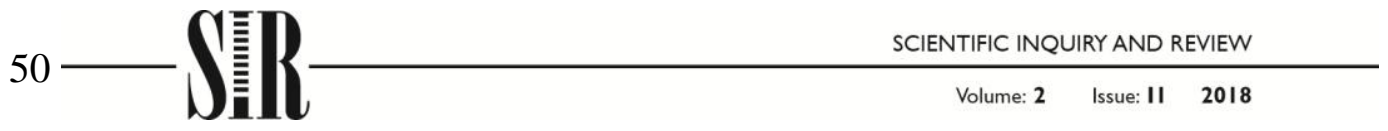


environmental and genetic factors seem to work up to varying degrees in various ethnic communities along with relative disease frequency and severity. A study conducted in workers handling leather tanning in Karachi, Pakistan showed a higher incidence of respiratory disorders, e.g., obstructive lung disease, asthma and other respiratory symptoms [80]. Asthma is more prevalent in female adults and people above 55 years of age, especially in the winter season [81]. In addition to the environmental factors, interleukins, especially IL-4 and single nucleotide polymorphism has been found to be significantly associated with rhinitis and asthma [82]. Recent studies indicate the significant association of different SNP sequences with asthmatic conditions such as rs3859192, rs3816470, rs12603332, rs6503525, on chromosome 17q21; and rs2569190 and rs2569191 in CD14; rs2243250 and rs2227284 in IL-4; rs1800896 in IL-10; rs1881457, rs20541 and rs1800925 in IL-13; rs2280091, rs2787094 and rs528557 in ADAM33 and rs 1131882 in TBXA2R genes. However, haplotype "CCTCAG" of SNPs e.g. rs7216389, rs12936231, rs7216558, rs1007654 rs9894164, and rs7212938 in $17 q 21$ and 'AAGTCG' of SNPs e.g. rs2280089, rs2280091, rs2280090, rs44707, rs612709 and rs528557 in ADAM-33 gene serve as a protective element against asthma susceptibility [85].

Genetic polymorphism on Glutathione-S-Transferase P1 and group specific component is found to be associated with an elevated risk of asthma in the country [83]. Folk medicines such as Cardamom (Elettaria cardamomum) are used as relaxants and bronchodilators are employed widely for treatment [84]. At present, there has been an increase in the occurrence of asthma among the Pakistani population; the main reason being low awareness regarding this disease in the general public. In addition, several misconceptions related to asthma were reported in a study by Irfan et al in 2017. The study showed that people have poor knowledge and a lot of misconceptions regarding asthma, e.g., side effects of inhaled medications, regarding asthma as an infectious and psychological disorder, rice and milk as a trigger for asthma, etc. [87].

\section{Conclusion and Recommendations}

The advances in the study of genetic mechanisms underlying asthma, its causes, stimulating factors and treatments are surely going to uncover new horizons in near future. The next generation of DNA sequencing and high through put and low-cost gene chip methods are helpful to accelerate research in this regard. The interaction of the potential genes involved in asthma with the environment is required for accurate evaluation of genetic effects. The assessment of the molecular based mechanisms of the genetic basis of asthma and other related respiratory diseases is necessary [34]. The identification of the genetic variants of asthma will help us understand the susceptibility factors and design new drugs for its prevention and treatment as well as the optimization of the present therapeutic strategies. It is also desirable to identify the susceptible individuals by genetic screening at an early 
age to prevent the onset of disease by avoiding exposure to possible allergens. In addition, there is a need to increase public awareness about the nature, causes and treatments of asthma.

\section{References}

[1] British Thoracic Society. British guideline on the management of asthma: A national clinical guideline. London: British Thoracic Society; 2009.

[2] World Health Organization. Asthma fact sheet no. 307. Retrieved from http://www.who.int/mediacentre/factsheets/fs307/en

[3] NHLBI. Guidelines for the diagnosis and management of Asthma (EPR-3) Retrieved from https://www.nhlbi.nih.gov/health-topics/guidelines-fordiagnosis-management-of-asthma

[4] Bracharier LB, Boner A, Charlsen HK, Eigenmann AP, Frischer T, Gotz M, et al. Diagnosis and treatment of asthma in childhood: A practical consensus report. Allergy. 2008;63: 5-34.

[5] Global Initiative for Asthma (GINA). Global strategy for asthma management and prevention. Retrieved from www.ginasthma.org

[6] Masoli M, Fabian D, Beasley R. The global burdens of asthma: Executive summary of GINA Dissemination committee report. Allergy. 2004;59: 469478.

[7] Definition, Pathophysiology and Pathogenesis of Asthma, and Natural History of Asthma. In Guidelines for the diagnosis and management of Asthma (EPR-3). Retrieved from https://www.nhlbi.nih.gov/health-topics/guidelinesfor-diagnosis-management-of-asthma

[8] Barnes P, Woolcock AJ. Difficult asthma. Eur Respir J. 1998;12: 1209-1218.

[9] Manniche L. Sacred luxuries: Fragrance, aromatherapy, and cosmetics in ancient Egypt. New York: Cornell University Press; 1999.

[10] Murray JF. Asthma respiratory medicine $5^{\text {th }}$ ed. Philadelphia, PA: Elsevier; 2010.

[11] Rosner F. The Life of Moses Maimonides, a Prominent Medieval Physician. Einstein Quart J Biol Med. 2002;19(3): 125-128.

[12] Thorowgood JC. On bronchial asthma. Br Med J. 1873;2(673): 600.

[13] Gaskoin G. On the treatment of asthma. Br Med J. 1872;1(587): 339.

[14] Berkart JB. The treatment of asthma. Br Med J. 1880;1(1016): 917-918.

[15] Doig RL. Epinephrine; especially in asthma. Calif State J Med. 1905;3(2): $54-55$.

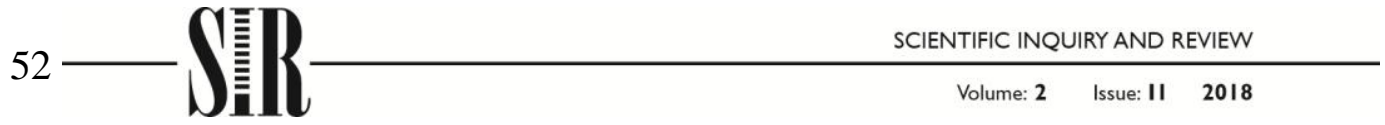


[16] Mutius E, Drazen JM. A patient with asthma seeks medical advice in 1828, 1928, and 2012. N Engl J Med. 2012;366(9): 827-834.

[17] Crompton G. A brief history of inhaled asthma therapy over the last fifty years. J Gen Pract Airways Group. 2006;15(6): 326-331.

[18] Opolski M, Wilson I. Asthma and depression: A pragmatic review of the literature and recommendations for future research. Clin Pract Epidemol Ment Health. 2005;1:18.

[19] Balmes J, Becklake M, Blanc P, Henneberger P, Kreiss K, Mapp C, et al. American thoracic society statement: Occupational contribution to the burden of airway disease. Am J Respir Crit Care Med. 2003;167:787-797.

[20] Janssens T, Verleden G, De-Peuter S, Van-Diest I, Vanden BO. Inaccurate perception of asthma symptoms: A cognitive-affective framework and implications for asthma treatment. Clin Psychol Rev. 2009;29:317-327.

[21] Chugg K, Barton C, Antic R, Crockett A. The impact of alexithymia on asthma patient management and communication with health care providers: A pilot study. J Asthma. 2009;46: 126-129.

[22] Daenen M, Rogiers C, Walle DV, Rochette F, Demedts M, Nemery B. Occupational asthma caused by palladium. Eur Respir J. 1999;13: 213-216.

[23] Balmes RJ. Can traffic-related air pollution cause asthma? Thorax. 2009;64: 645-646.

[24] Chan-Yeung M, Malo JL. Occupational respiratory diseases associated with forest products industries. St. Louis: Mosby; 1996. P. 637-653.

[25] Algranti E, Mendonça CME, Ali AS, Kokron MC, Raile V. Occupational asthma caused by Ipe (Tabebuia spp) dust. J Invest Allergol Clin Immunol. 2005;15(1): 81-83.

[26] Sauni R, Oksa P, Vattulainen K, Uitti J, Palmroos P, Roto P. Effects of asthma on the quality of life and employment of construction workers. Occup Med. 2001;51(3): 163-167.

[27] Parsons PJ, Hallstrand ST, Mastronarde GJ, Kaminsky AD, Rundell WK, Hull HJ, et al. An official American thoracic society clinical practice guideline: Exercise-induced Bronchoconstriction. Am J Respir Crit Care Med. 2013;187(9): 1016-1027.

[28] Brunekreef B, Hoek G, Roemer W, Zee SDV. Panel studies for investigating the acute health effects of air pollution. Eur Respir Rev. 1998;8: 131-134.

[29] Johnston SL, Pattemore PK, Sanderson G, Smith S, Lampe F, Josephs L, Community study of role of viral infections in exacerbations of asthma in school children in the community. Br Med J. 1995;310:1225-1229. 
[30] Siracusa A, DeBlay F, Folletti I. Asthma and exposure to cleaning products: A European academy of allergy and clinical immunology task force consensus statement. Allergy. 2013;68: 1532-1545.

[31] Thickett KM, McCoach JS, Gerber JM. Occupational asthma caused by chloramines in indoor swimming-pool air. Eur Respir J. 2002;19: 827-832.

[32] Weinberger M. Can we prevent exacerbations of asthma caused by common cold viruses? J Allergy Clin Immunol. 2010;126: 770-771.

[33] Perera F, Tang WY, Herbstman J, Tang D, Levin L, Miller R. Relation of DNA methylation of 5'-CpG island of ACSL3 to transplacental exposure to airborne polycyclic aromatic hydrocarbons and childhood asthma. PLoS. 2009;4: 4488.

[34] Meng FJ, Rosenwasser JL. Unraveling the genetic basis of asthma and allergic diseases. Allergy Asthma Immunol Res. 2010;2(4): 215-227.

[35] Busse WW, Lemanske RF. Asthma. N Engl J Med. 2001;344(5): 350-362.

[36] Stevenson DD, Szczeklik A. Clinical and pathologic perspectives on aspirin sensitivity and asthma. J Allergy Clin Immunol. 2006;118(4): 773-786.

[37] Holgate ST, Polosa R. The mechanisms, diagnosis, and management of severe asthma in adults. Lancet. 2006;368(9537): 780-793.

[38] Duffy DL, Martin NG, Battistutta D, Hopper JL, Matthews JD. Genetics of asthma and hay fever in Australian twins. Am Rev Respir Dis. 1990;142: 1351-1358.

[39] Sandford A, Weir T, Pare P. The genetics of asthma. Am J Respir Crit Care Med. 1996;153: 1749-1765.

[40] Pinto LA, Stein RT, Kabesch M. Impact of genetics in childhood asthma. $J$. Pediatr. 2008;84: 68-75.

[41] Moffatt MF, Gut IG, Demenais F, Strachan DP, Bouzigon E, Heath S. A large-scale, consortium-based genome-wide association study of asthma. $N$ Engl J Med. 2010;363: 1211-1221.

[42] Khoury MJ, Beaty TH, Cohen BH. Genetic approaches to familial aggregation III: Linkage analysis. Oxford: Oxford University Press; 1993. p. 284.

[43] Eerdewegh PV, Little RD, Dupuis J, Mastro RGD, Falls K, Simon J, et al. Association of the ADAM33 gene with asthma and bronchial hyperresponsiveness. Nature. 2002;418: 426-430. 
[44] Chavanas S, Bodemer C, Rochat A, Hamel-Teillac D, Ali M, Irvine AD, et al. Mutations in SPINK5, encoding a serine protease inhibitor, cause Nether ton syndrome. Nat Genet. 2000;25: 141-142.

[45] Mathias RA, Grant AV, Rafaels N, Hand T, Gao L, Vergara C, et al. A genome-wide association study on African-ancestry populations for asthma. J Allergy Clin Immunol. 2010;125: 336-346.

[46] Balaci L, Spada MC, Olla N, Sole G, Loddo L, Anedda F, et al. IRAK-M is involved in the pathogenesis of early-onset persistent asthma. Am J Hum Genet. 2007;80: 1103-1114.

[47] Laitinen T, Polvi A, Rydman P, Vendelin J, Pulkkinen V, Salmikangas P, et al. Characterization of a common susceptibility locus for asthma-related traits. Science. 2004;304: 300-304.

[48] Nicolae D, Cox NJ, Lester LA, Schneider D, Tan Z, Billstrand C, et al. Fine mapping and positional candidate studies identify HLA-G as an asthma susceptibility gene on chromosome 6p21. Am J Hum Genet. 2005;76: 349357.

[49] Zhang Y, Leaves NI, Anderson GG, Ponting CP, Broxholme J, Holt R, et al. Positional cloning of a quantitative trait locus on chromosome 13q14 that influences immunoglobulin E levels and asthma. Nat Genet. 2003;34: 181186.

[50] Risch N, Merikangas K. The future of genetic studies of complex human diseases. Science. 1996;273: 1516-1517.

[51] Wu AC, Tantisira K, Li L, Schuemann B, Weiss S. Repeatability of response to asthma medications. J Allergy Clin Immunol. 2009;123(2): 385-390.

[52] Laitinen T, Rasanen M, Kaprio J, Koskenvuo M, Laitinen LA. Importance of genetic factors in adolescent asthma: A population-based twin-family study. Am J Respir Crit Care Med. 1998;157: 1073-1078.

[53] Romanet-Manent S, Charpin D, Magnan A, Lanteaume A, Vervloet D. Allergic vs non-allergic asthma: What makes the difference? Allergy. 2002;57(7):607-613.

[54] Cohn L, Elias JA, Chupp GL. Asthma: Mechanisms of disease persistence and progression. Annu Rev Immunol. 2004;22:789-815.

[55] Meyer EH, DeKruyff RH, Umetsu DT. T cells and NKT cells in the pathogenesis of asthma. Annu Rev Med. 2008;59:281-292.

[56] Ho IC, Pai SY. GATA-3 - not just for Th2 cells anymore. Cell Mol Immunol. 2008;4:15-29. 
[57] Brightling CE. Mast-cell infiltration of airway smooth muscle in asthma. $N$ Engl J Med. 2002;346:1699-1705.

[58] Strachan DP. Hay fever, hygiene and household size. Br Med J. 1989;299(6710):1259-1260.

[59] Robinson DS, Hamid Q, Ying S, Tsicopoulus A, Barkans J, Bentley AM, et al. Predominant Th2-like bronchoalveolar T-lymphocyte population in atopic asthma. N Eng J Med. 1992;326(5):298-304.

[60] Shirakawa T, Enomoto T, Shimazu S, Hopkin JM. The inverse association between tuberculin responses and atopic disorders. Science. 1997;275(5296):77-79.

[61] Bullens DM, Truyen E, Coteur L, Dilissen E, Hellings PW, Dupont LJ, et al. IL-17 mRNA in sputum of asthmatic patients: Linking $\mathrm{T}$ cell driven inflammation and ranulocyte influx? Respir Res. 2006;7:135.

[62] O'Byrne PM, Parameswaran K. Pharmacological management of mild or moderate persistent asthma. Lancet. 2006;368(9537): 794-803.

[63] Sorkness RL, Bleecker ER, Busse WW, Calhoun WJ, Castro M, Chung KF. Lung function in adults with stable but severe asthma: Air trapping and incomplete reversal of obstruction with bronchodilation. J Appl Phys. 2008;104(2): 394-403.

[64] Lemanske RF Jr, Mauger DT, Sorkness CA, Jackson DJ, Boehmer SJ, Martinez FD. Step-up therapy for children with uncontrolled asthma receiving inhaled corticosteroids. $N$ Engl J Med. 2010;362: 975-985.

[65] Woodcock A, Bleecker ER, Lotvall J, O’Byrne PM, Bateman ED, Medley H. Efficacy and safety of fluticasone furoate/vilanterol compared with fluticasone propionate/salmeterol combination in adult and adolescent patients with persistent asthma: A randomized trial. Chest. 2013;144: 12221229.

[66] Expert Panel Report 3 (EPR-3). Guidelines for the diagnosis and management of asthma-summary report. J Allergy Clin Immunol. 2007;120(5): 94-138.

[67] Guilbert TW, Morgan WJ, Zeiger RS, Mauger DT, Boehmer SJ, Szefler SJ. Long-term inhaled corticosteroids in preschool children at high risk for asthma. N Engl J Med. 2006;354:1985-1997.

[68] Spina D. PDE4 inhibitors: Current status. Br J Pharmacol. 2008;155: 308315.

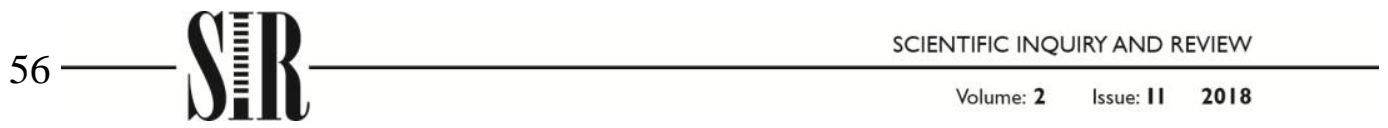


[69] Joos S, Miksch A, Szecsenyi J, Wieseler B, Grouven U, Kaiser T. Montelukast as add-on therapy to inhaled corticosteroids in the treatment of mild to moderate asthma: A systematic review. Thorax. 200;63: 453-462.

[70] Kerstjens HA, Engel M, Dahl R, Paggiaro P, Beck E, Vandewalker M. Tiotropium in asthma poorly controlled with standard combination therapy. N Engl J Med. 2012;367:1198-1207.

[71] Burch J, Griffin S, McKenna C, Walker S, Paton J, Wright K. Omalizumab for the treatment of severe persistent allergic asthma in children aged 6-11 years: A NICE single technology appraisal. Pharmacoeconomics. 2012;30: 991-1004.

[72] Cox PG, Miller J, Mitzner W, Leff AR. Radio frequency ablation of airway smooth muscle for sustained treatment of asthma: Preliminary investigations. Eur Respir J. 2004;24: 659-663.

[73] Diaz JE, Dubin R, Gaeta TJ, Pelczar P, Bradley K. Efficacy of atropine sulphate combined with albuterol in the treatment for acute asthma. Acad Emerg Med. 1997;4: 107-113.

[74] Busse PJ, Schofield B, Brimingham N, Yang N, Wen MC, Zhang T. The traditional Chinese herbal formula ASHMI inhibits lung inflammation in antigen-sensitized and antigen-challenged aged mice. Ann Allergy Asthma Immunol. 2010;104: 236-246.

[75] Quintao NML, Meyre-Silva C, Silva GF, Antonialli CS, Rocha LW, Silva RM. Aleurites moluccana (L) wild leaves: Mechanical antinociceptive properties of a standardized direct extract and its chemical markers. Evid Based Complement Altern Med. 2011;1155-1165.

[76] Yin ML, Xu DY, Peng LL, Duan T, Liu YJ, Xu Z, et al. Transgelin-2 as a therapeutic target for asthmatic pulmonary resistance. Sci Transl Med. 2018;10:1-10.

[77] Saglani S, Lui S, Ullmann N, Campbell GA, Sherburn RT, Mathie SA. IL-33 promotes airway remodeling in pediatric patients with severe steroid resistant asthma. J Allergy Clin Immunol. 2013;132: 676-685.

[78] Wu H, Romieu I, Shi M, Hancock DB, Li H, Sienra-Monge JJ, et al. Evaluation of candidate genes in a genome-wide association study of childhood asthma in Mexicans. J Allergy Clin Immunol. 2010;125: 321-327.

[79] Wright RJ, Cohen S, Carey V, Weiss ST, Gold DR. Parental stress as a predictor of wheezing in infancy: A prospective birth-cohort study. Am J Respir Crit Care Med. 2002;165: 358-365.

[80] Rietveld S, vanBeest I. Rollercoaster asthma: When positive emotional stress interferes with dyspnea perception. Behav ReD Ther. 2007;45:977-987. 
[81] Dirks JF, Robinson SK, Dirks DL. Alexithymia and the psychomaintenance of bronchial asthma. Psychother Psychosom. 1981;36: 63-71.

[82] Miles JF, Garden GM, Tunnicliffe WS, Cayton RM, Ayres JG. Psychological morbidity and coping skills in patients with brittle and non-brittle asthma: A case-control study. Clin Exp Allergy. 1997;27: 1151-1159.

[83] Scott KM, VonKorff M, Ormel J, Zhang MY, Bruffaerts R, Alonso J. Mental disorders among adults with asthma: Results from the World Mental Health Survey. Gen Hosp Psychiatry. 2007;29: 123-133.

[84] Delmas MC, Guignon N, ChanChee C, Fuhrman C, Herbet JB, Gonzalez L. Asthma and major depressive episode in adolescents in France. J Asthma. 2011;48: 640-646.

[85] Goodwin RD, Robinson M, Sly PD, McKeague IW, Susser ES, Zubrick SR. Severity and persistence of asthma and mental health: A birth cohort study. Psychol Med. 2013;43:1313-1322.

[86] Vieira AA, Santoro IL, Dracoulakis S, Caetan LB, Fernandes AL. Anxiety and depression in asthma patients: Impact on asthma control. J Bras Pneumol. 2011;37: 13-18.

[87] Bratek A, Zawada K, Beil-Gawełczyk J, Beil S, Sozańska E, Krysta K. Depressiveness, symptoms of anxiety and cognitive dysfunctions in patients with asthma and chronic obstructive pulmonary disease (COPD); possible associations with inflammation markers: A pilot study. J Neural Transm. 2014.

[88] Noori SMH, Waqar MA. Prevalence of allergies and asthma in Pakistan. World Allergy Organ J. 2007;206-207.

[89] Drake KA, Galanter JM, Burchard EG. Race, ethnicity and social class and the complex etiologies of asthma. Pharmacogenomics. 2008;9(4):453-462.

[90] Jamal A, Mehmood A, Putus T, Savolainen H, Liesivuori J. Prevalence of respiratory symptoms, bronchial asthma and obstructive lung disease among tannery workers. Peertechz J Environ Sci Toxicol. 2017;2(1): 033-042.

[91] Ahmed A, Ahmed F, Raza MZ, Ghani A, Rizvi N. A descriptive analysis of asthma exacerbations and its mortality in Karachi, Pakistan. J Allergy Ther. 2013;11: 004.

[92] Micheal S, Minhas S, Ishaque M, Ahmed F, Ahmed A. IL-4 Gene Polymorphisms and their association with atopic asthma and allergic rhinitis in Pakistani patients. J Investig Allergol Clin Immunol. 2013;23(2): 107-111.

[93] Ghani MU, Sabar MF, Shahid M, Awan FI Akram M. A report on asthma genetics studies in Pakistani population. Adv. Life Sci. 2017;4(2):33-38.

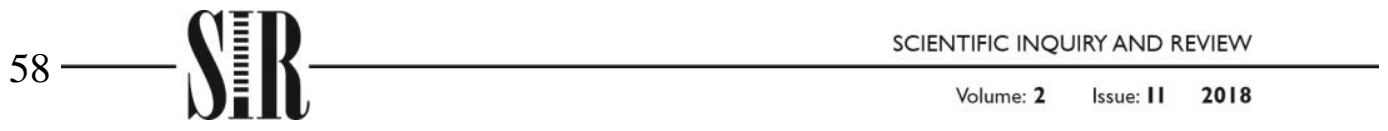


[94] Al-Arifa N, Jahan N. Association of Glutathione-S-Transferase P1 (GSTP1) and Group-Specific Component (GC) polymorphism with the risk of asthma in Pakistani population. Pak J Zool. 2016;48(4): 937-942.

[95] Khan A, Khan JQ, Gilani HA. Pharmacological basis for the medicinal use of cardamom in asthma. Bangladesh J Pharmacol. 2011;6: 34-37.

[96] Irfan O, Irfan B, Khan AZ, Tahir M, Zubairi SBA, Khan AJ, Knowledge about asthma: A cross-sectional survey in 4 major hospitals of Karachi, Pakistan. J Pak Med Assoc. 2017;67(11):1787-1790. 